Supporting Information

S-1 


\section{Conjugation of a Scintillator Complex and Gold Nanorods for Dual-Modal Image-Guided Photothermal and X-Ray-Induced Photodynamic Therapy of Tumors}

Li Luo, $\uparrow_{\dagger}^{\#}$ Wenjing Sun,, ,\# Yushuo Feng, $\uparrow$ Ruixue Qin, $\dagger$ Jinghui Zhang,, Dandan

Ding, $\uparrow$ Tianhang Shi, $\uparrow$ Xiangmei Liu, $\uparrow$ Xiaoyuan Chen,,\|\| Hongmin Chen $*, \uparrow$

$\uparrow$ State Key Laboratory of Molecular Vaccinology and Molecular Diagnostics \& Center for Molecular Imaging and Translational Medicine, School of Public Health, Xiamen University, Xiamen 361102, China

\$ Key Laboratory for Organic Electronics and Information Displays \& Jiangsu Key Laboratory for Biosensors, Institute of Advanced Materials (IAM), Nanjing University of Posts and Telecommunications (NUPT), Nanjing 210023, P. R. China | Laboratory of Molecular Imaging and Nanomedicine, National Institute of Biomedical Imaging and Bioengineering (NIBIB), National Institutes of Health (NIH), Bethesda, MD 20892, USA

\# These authors contributed equally. 


\section{Supporting information for experimental section}

\section{Materials}

Tetrachloroauric acid $\left(\mathrm{HAuCl}_{4} \cdot 3 \mathrm{H}_{2} \mathrm{O}, 99.9 \%\right)$, sodium borohydride $\left(\mathrm{NaBH}_{4}, 99 \%\right)$, cetyltrimethyl ammonium bromide (CTAB, 99\%), tetraethyl orthosilicate (TEOS), ascorbic acid (99\%), silver nitrate $\left(\mathrm{AgNO}_{3}, 99 \%\right)$, 3-aminopropyl-triethoxysilane (APTES, 99\%), NHS-PEG $3400-\mathrm{COOH}, \quad \mathrm{N}$-(3-dimethylaminopropyl)-N ' ethylcarbodiimide hydrochloride (EDC, 99\%), N-hydroxysuccinimide (NHS, 98\%), 9,10-anthracenediylbis (methylene) dimalonic acid (ABDA, 99\%), singlet oxygen sensor green (SOSG), and 4-nitrophenyl chloroformate 3-(4,5-dimethylthiazol-2-yl)2,5-diphenyltetrazolium bromide (MTT) were purchased from Sigma-Aldrich (MO, USA). Methanol, ethanol, dimethyl sulfoxide (DMSO) and dimethylformamide (DMF) were supplied by Sinopharm Chemical Reagent Co., Ltd. Ultrapure water was obtained from a Millipore autopure system with resistivity of $18.2 \mathrm{M} \Omega$. All chemicals were analytical grade and used without further purification unless noted. Fetal bovine serum (FBS) was purchased from HyClone Inc. Breast cancer cell line (4T1) was obtained from Institute of Biochemistry and Cell Biology (Shanghai, China). Male BALB/c mice were purchased from Shanghai SLAC Laboratory Animal Co. Ltd (Shanghai, China).

\section{Characterization}

Transmission electron microscopy (TEM) images were carried out on a JEM-2100 transmission electron microscope operating at $200 \mathrm{kV}$ (JEOL Ltd., Tokyo, Japan). The crystal structure had been proved by powder X-ray diffractometer (XRD) using Ultima IV X-ray powder diffractometer (Rigaku Co., Japan). Hydrodynamic size and $\zeta$ potential were measured using ZetaSizer Nano-ZS size analyzer (Malvern Ltd., UK). Absorption spectra were recorded using a UV-Vis spectrometer (Agilent Cary60, USA). The mini-X X-ray tube (Amptek Inc.) was used as the X-ray source $(50 \mathrm{kV}, 70 \mu \mathrm{A})$. And X-ray excited optical luminescence (XEOL) was measured using an Ocean Optics QE Pro optical bench. Photothermal irradiation was carried out using an $808 \mathrm{~nm}$ semiconductor laser unit (KS3-11312-110, BWT, Beijing Kaipulin Co., Ltd., China). 
The Cellular fluorescence images were examined using a laser scanning confocal microscopy (Olympus FV1200, Japan). CT images were recorded using a CT system (Siemens Inveon micro-CT instrument). Photoacoustic imaging was performed using a Vevo LAZR-X system (FUJIFILM VisualSonics Inc., Toronto, Canada).

\section{Singlet oxygen $\left({ }^{1} \mathrm{O}_{2}\right)$ production in solutions}

$0.1 \mathrm{~mL}$ HP or GSE-HP solution $\left(0,20,40,60,80,100100 \mu \mathrm{g} \cdot \mathrm{mL}^{-1}\right)$ was added into an enzyme strip containing $0.1 \mathrm{~mL}$ ABDA $\left(100 \mu \mathrm{g} \cdot \mathrm{mL}^{-1}\right)$. The solution was irradiated by X-ray $(1,2,3$, 4, 5 Gy). The UV-Vis absorption was measured after the irradiation.

\section{Photothermal effect and photothermal conversion efficiency}

Photothermal effect was monitored with a FLIR A $\times 5$ camera (FLIR Systems Inc., Wilsonville, OR, USA) when $0.1 \mathrm{~mL}$ samples of GSE-HP $\left(100 \mu \mathrm{g} \cdot \mathrm{mL}^{-1}\right)$ under laser irradiation $\left(808 \mathrm{~nm}, 0.8 \mathrm{~W} \cdot \mathrm{cm}^{-2}\right)$ for $600 \mathrm{~s}$. The photothermal conversion efficiency $(\eta)$ was calculated using the following reported equation: ${ }^{1}$

$$
\eta=\frac{h S\left(T_{\max }-T_{\text {surr }}\right)-Q_{\text {dis }}}{I\left(1-10^{-A_{808}}\right)}
$$

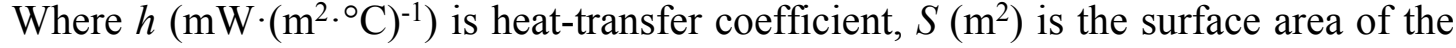
container, $T_{\max }$ is the equilibrium temperature, and $T_{\text {surr }}$ is the surrounding temperature. In this experiment, $T_{\max }-T_{\text {surr }}$ was $23.4{ }^{\circ} \mathrm{C}$. The $Q_{D i s}(\mathrm{~mW})$ is the heat dissipation from light absorbed by a cuvette sample wall itself and it was measure to be $11.2 \mathrm{~mW}$. I is the laser power $(0.8 \mathrm{~W})$ and $A_{808}$ is the absorbance (0.798) of GSE-HP at $808 \mathrm{~nm}$. The value of $h S$ was calculated according to these following equations:

$$
\begin{gathered}
\tau_{S}=\frac{\sum_{i} m_{i} C_{p, i}}{h S} \\
t=-\tau_{S} \ln (\theta) \\
\theta=\frac{T-T_{\text {surr }}}{T_{\max }-T_{\text {surr }}}
\end{gathered}
$$

$\tau_{s}$ was determined to be $345.56 \mathrm{~s}$, thus $h S$ was deduced to be $11.55 \mathrm{~mW} \cdot{ }^{\circ} \mathrm{C}^{-1}$ (substituted $m=1 \mathrm{~g}, C=4.2 \mathrm{~J} \cdot \mathrm{g}^{-1} \cdot \mathrm{K}^{-1}$ in Equation (3)). Finally, the photothermal conversion efficiency $(\eta)$ was calculated to be $38.4 \%$ from Equation (2). 


\section{In vitro CT and Photoacoustic (PA) imaging}

For in vitro imaging experiments, $200 \mu \mathrm{L}$ of GSE-HP of different concentrations $(0$, $6.25,12.5,25,50,100$, and $200 \mu \mathrm{g} \cdot \mathrm{mL}^{-1}$ ) were added into PCR tubes to perform CT and photoacoustic imaging. CT imaging parameters were as follows: effective pixel size, $112.93 \mu \mathrm{m}$; field of view, $57.82 \mathrm{~mm} \times 86.73 \mathrm{~mm}$; binning, $4 \times 4$; rotation steps, 180; exposure time, $300 \mathrm{~ms} \cdot$ rotation $^{-1} ; 80 \mathrm{kV}, 500 \mu \mathrm{A}$. Images of phantom $\mathrm{CT}$ images were analyzed with Kodak Molecular Imaging Software. HU values were measured by the Siemens Inveon micro-CT software. PA imaging was performed using a Vevo LAZR-X system (FUJIFILM VisualSonics Inc., Toronto, Canada) equipped with a 40 $\mathrm{MHz}, 256-$ element linear array transducer on tumors. A 780-nm excitation filter was used.

\section{Cell toxicity assay}

$4 \mathrm{~T} 1$ breast cancer cell line was incubated in DMEM medium under $37^{\circ} \mathrm{C}$ within $5 \%$ $\mathrm{CO}_{2}$ atmosphere. The cells were pipetted into $96-$-well plates (5000 cells per well) and incubated for $24 \mathrm{~h}$. Then, the as-prepared samples of indicated concentrations $(0,6.25$, $12.5,25,50,100 \mu \mathrm{g} \cdot \mathrm{mL}^{-1}$ ) were added to the cell culture medium and incubated with the cells for another $24 \mathrm{~h}$. The cytotoxicity was evaluated according to the standard MTT assays protocol.

\section{Cellular uptake}

Typically, 4T1 cells $\left(1 \times 10^{5}\right.$ cells $)$ were seeded on glass-bottomed microwell dishes $(\varnothing$ $=10 \mathrm{~mm})$. After $24 \mathrm{~h}, 2 \mathrm{~mL}$ GSE-HP $\left(100 \mu \mathrm{g} \cdot \mathrm{mL}^{-1}\right)$ was added and incubated with cells for another $24 \mathrm{~h}$. Cells were washed with PBS and pre-stained with $5 \mu \mathrm{M}$ DAPI for $30 \mathrm{~min}$. And then washed again before replenishing with fresh medium. The fluorescence images were imaged under a confocal laser scanning microscope (Olympus FV1200). 


\section{In vitro X-PDT and PTT efficacy assay}

$4 \mathrm{~T} 1$ cells $\left(1 \times 10^{4}\right.$ cells $)$ were seeded into 96 -well plates and incubated for $24 \mathrm{~h}$ at $37^{\circ} \mathrm{C}$ with $5 \% \mathrm{CO}_{2}$. Then, the cells were incubated for another $24 \mathrm{~h}$ with $100 \mu \mathrm{L}$ various composites including GSE-HP suspension at different concentration $(0,6.25,12.5,25$, $\left.50,100 \mu \mathrm{g} \cdot \mathrm{mL}^{-1}\right)$ in fresh medium and washed three times with PBS. The cells were received different treatments: 1) no treatment, 2) X-PDT (X-ray: 2 Gy), 3) PTT (808 nm laser: $\left.\left.0.8 \mathrm{~W} \cdot \mathrm{cm}^{-2}, 10 \mathrm{~min}\right), 4\right) \mathrm{X}-\mathrm{PDT}+\mathrm{PTT}(\mathrm{X}$-ray: 2 Gy $+808 \mathrm{~nm}$ laser: 0.8 $\left.\mathrm{W} \cdot \mathrm{cm}^{-2}, 10 \mathrm{~min}\right)$. Then the cells were further incubated for $24 \mathrm{~h}$ in DMEM, and cell viability was measured by the MTT assay.

To stain live and dead cells, the cells of different groups were incubated with calcein$\mathrm{AM}(4 \mu \mathrm{M})$ and propidium iodide $(4 \mu \mathrm{M})$ for $30 \mathrm{~min}$ at $37^{\circ} \mathrm{C}$, respectively. Cellular fluorescence images were then examined using an Olympus FV1200 laser scanning confocal microscope.

\section{In vitro ${ }^{1} \mathrm{O}_{2}$ production}

$4 \mathrm{~T} 1$ cells $\left(1 \times 10^{5}\right.$ cells $)$ were seeded in glass-bottomed microwell dishes $(\varnothing=10 \mathrm{~mm})$ and incubated for $24 \mathrm{~h}$ at $37^{\circ} \mathrm{C}$. The cells were then incubated with $100 \mu \mathrm{g} \cdot \mathrm{mL}^{-1}$ of GSE-HP for $24 \mathrm{~h}$ before being washed with PBS for three times and pre-stained with 5 $\mu \mathrm{M}$ SOSG for $30 \mathrm{~min}$. Next, the cells were washed with PBS and irradiated by X-ray ( 2 Gy). Then the cells were incubated with $5 \mu \mathrm{M}$ DAPI for $30 \mathrm{~min}$ and the images were acquired on an Olympus FV1200 confocal laser scanning microscope using $473 \mathrm{~nm}$ laser with a FITC filter.

\section{Animal experiments}

Male BALB/c mice were purchased from Shanghai SLAC Laboratory Animal Co. Ltd (Shanghai, China). All the animal experiments were carried out according to the guidelines of the Regional Ethics Committee for Animal Experiments and the Care Regulations approved by the Institutional Animal Care and Use Committee of Xiamen University. 


\section{In vivo bio-distribution and blood clearance}

First, tumor-bearing mice were constructed by subcutaneously injecting of $4 \times 10^{6} 4 \mathrm{~T} 1$ cells into the back of the hind leg. BALB/c mice (4 6 weeks old) were used for the tumor model establishment and intravenously (i.v.) injected with GSE-HP ( $\left.8 \mathrm{mg} \cdot \mathrm{kg}^{-1}\right)$. To confirm the in vivo distribution and blood clearance of GSE-HP nanoparticles, mice were sacrificed at $2,4,6,8,24$, and $48 \mathrm{~h}$ post-injection $(\mathrm{n}=3)$. The main organs (livers, heart, lungs, spleen, kidneys, stomach, intestine, brain, muscle, and tumor) and blood were weighed and digested using $\mathrm{HNO}_{3}-\mathrm{H}_{2} \mathrm{O}_{2}$ mixture. The Au concentration in all samples were determined by ICP-MS and deduced as the percentage of injected dose per gram of tissue $(\% \mathrm{ID} / \mathrm{g})$. The in vivo blood circulation half-life of GSE-HP was calculated using the double-component pharmacokinetic model.

\section{Serum-chemistry and complete blood analysis}

To verify the biosafety, BALB/c mice were intravenously injected with GSE-HP (20 $\left.\mathrm{mg} \cdot \mathrm{kg}^{-1}\right)$. Blood samples were collected from the mice eye socket vein for serum chemistry and complete blood analysis at day 3 and 7 after injection $(n=3)$. The results were compared with bloods from the same mice before injection. The blood serum samples were analyzed using an Auto Biochemistry Analyzer (Mindray, BS-220) for some liver and renal function markers: alanine transaminase (ALT), aspartate transaminase (AST), and blood urea nitrogen (UREA). For complete blood analysis, a series of indicators like white blood cell, red blood cell, hemoglobin, etc., were measured using an Auto Hematology Analyzer (Mindray, BC-2600).

\section{Statistical Analysis}

All data were calculated and presented as mean \pm standard deviation. Comparison between two groups were analyzed with a Student's t-test ${ }^{*}: \mathrm{p}<0.05,{ }^{*}$ : $\mathrm{p}<0.01$, and $* * *: \mathrm{p}<0.001)$. 
Supporting information for figures

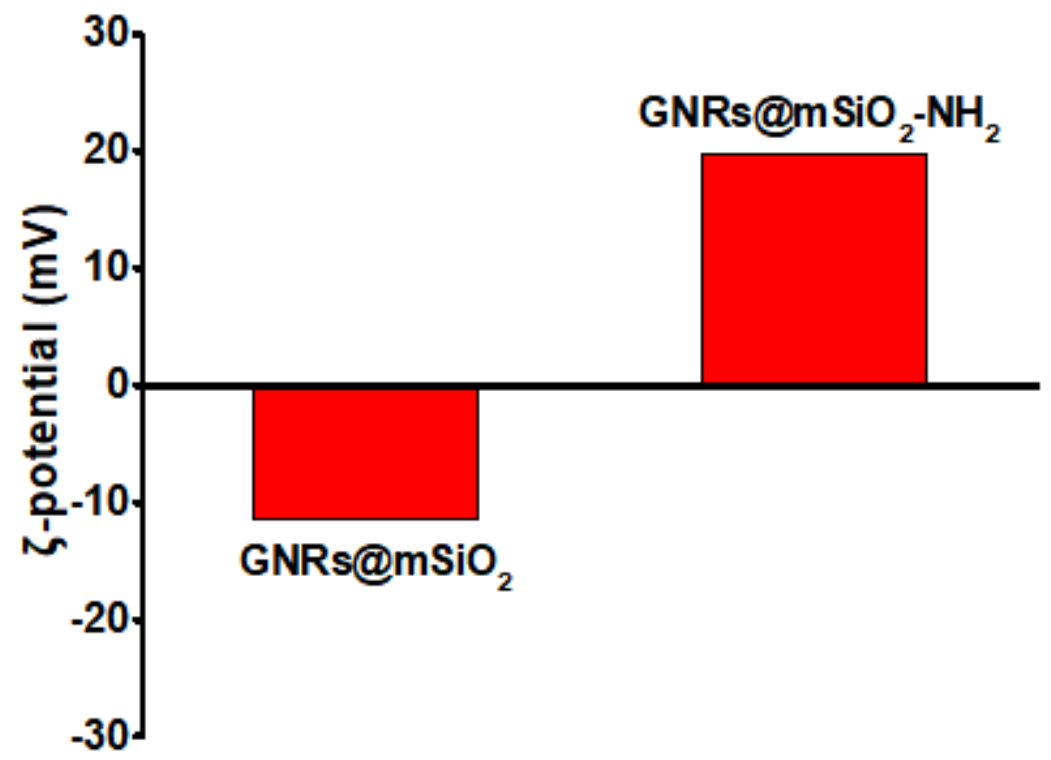

Figure S1. Zeta potential of GNRs@ $@ \mathrm{mSiO}_{2}$ and GNRs@mSiO $2-\mathrm{NH}_{2}$. 

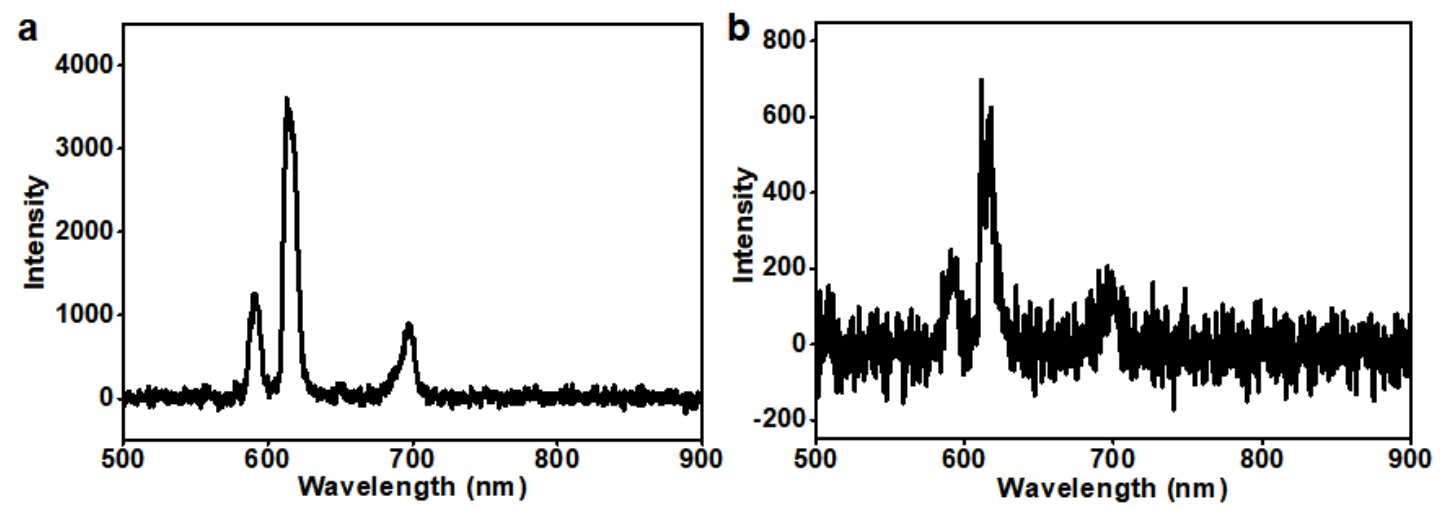

Figure S2. The XEOL spectrum of (a) EuBA and (b) APTES-EuBA. 

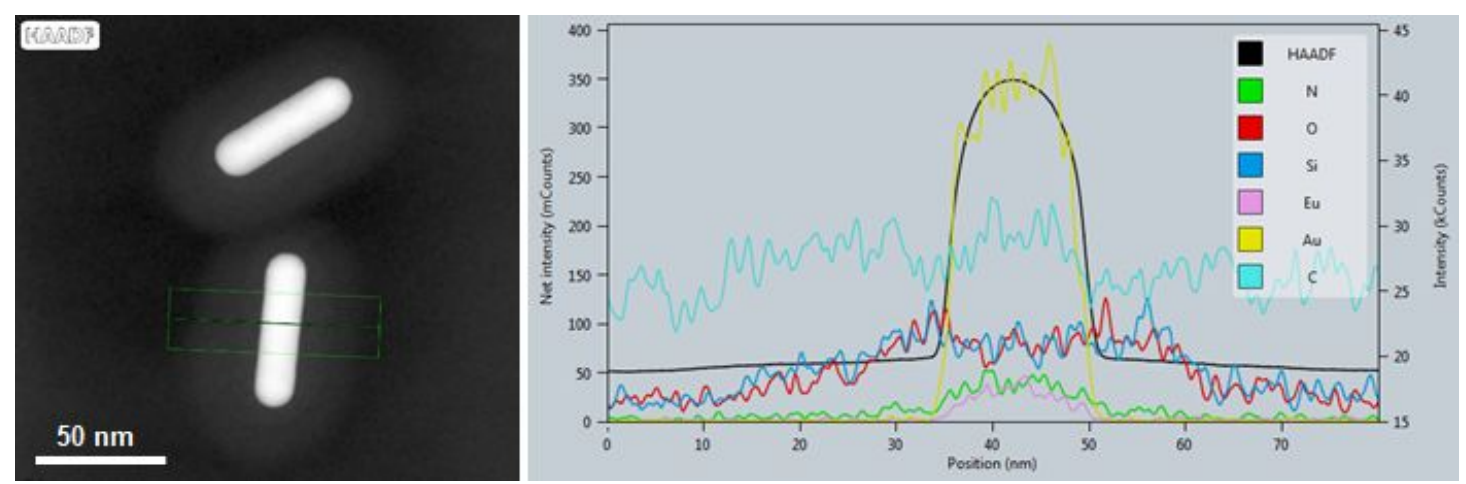

Figure S3. EDS analysis of GSE-HP. 

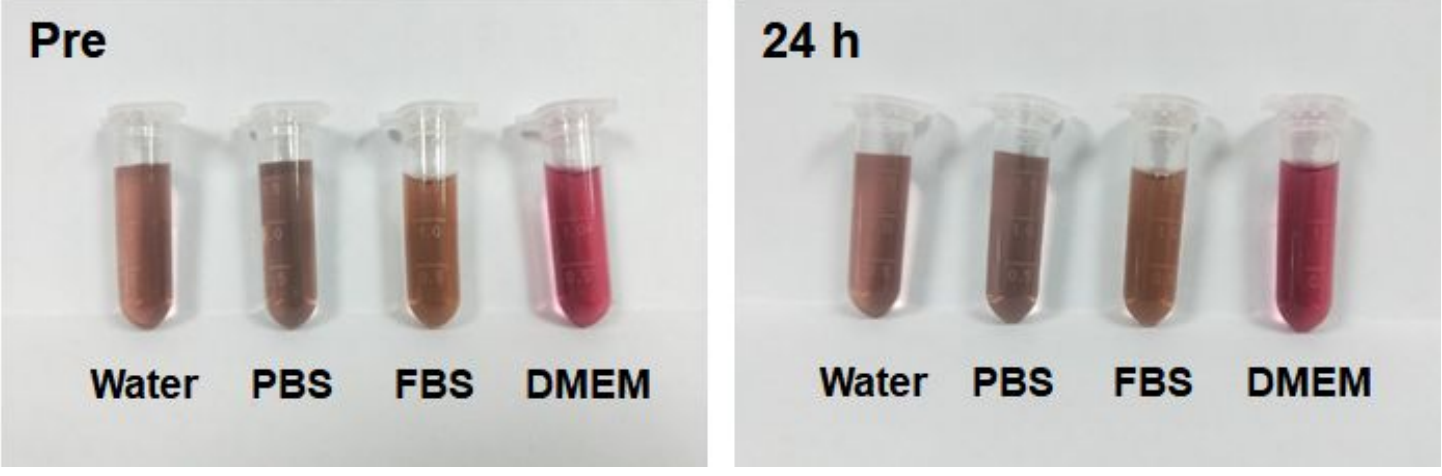

Figure S4. In vitro stability of GSE-HP dispersed in different medium (water, PBS, FBS, and DMEM). 

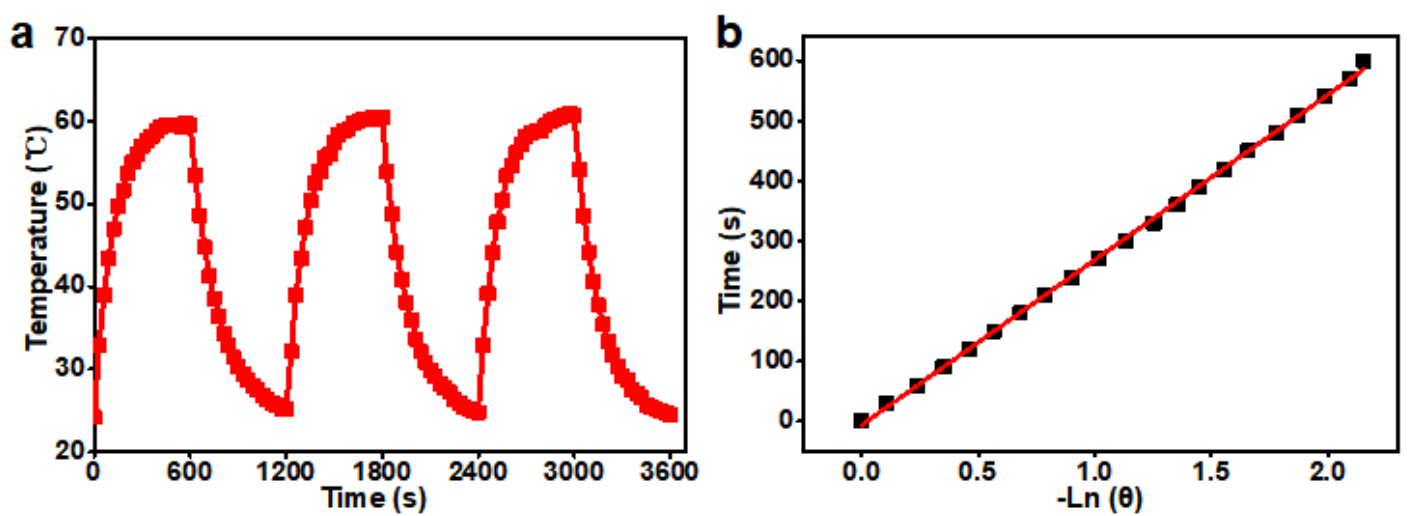

Figure S5. (a) Temperature variations of GSE-HP under continuous irradiation using $808 \mathrm{~nm}$ laser for several cycles. (b) The time constant for heat transfer from the system was determined to be $\tau_{\mathrm{s}}=274.94 \mathrm{~s}$ by applying the linear time data from the cooling period (from $600 \mathrm{~s}$ to $1200 \mathrm{~s}$ ) versus negative natural logarithm of the driving force temperature obtained from the cooling stage. 

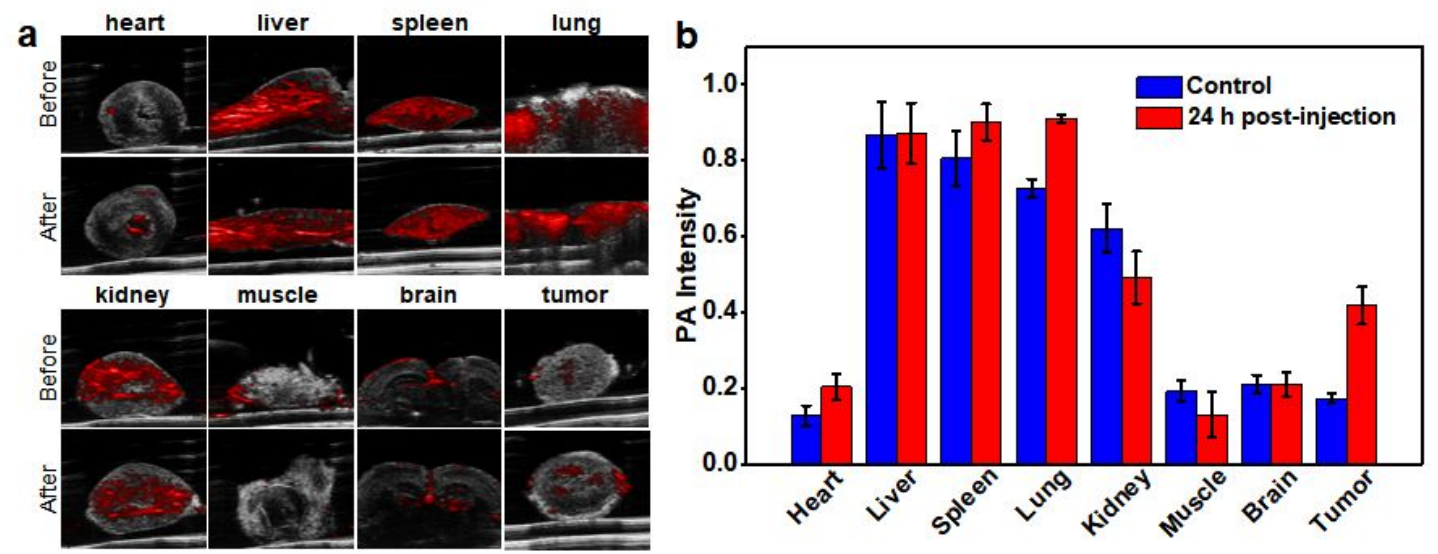

Figure S6. Photoacoustic (PA) images (a) and corresponding PA signals (b) of main tissues and tumor before and after injection with GSE-HP. 

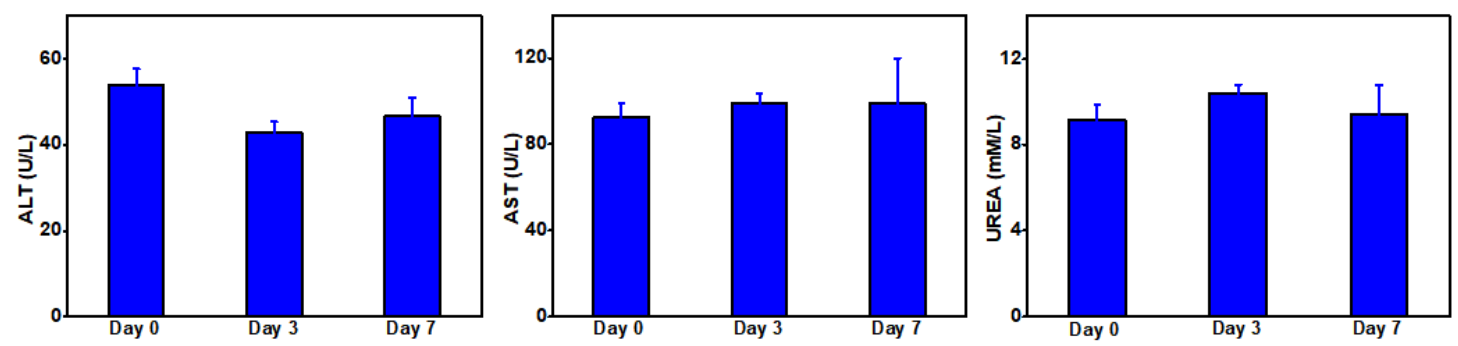

Figure S7. Serum chemistry of mice treated with GSE-HP. Data are mean \pm s.d. ALT, alanine transaminase; AST, aspartate transaminase; UREA, blood urea nitrogen. Mice were intravenously treated with GSE-HP $\left(8 \mathrm{mg} \cdot \mathrm{kg}^{-1}\right)$. Blood samples were collected for serum chemistry analysis on day 0,3 and 7 after treatment. 

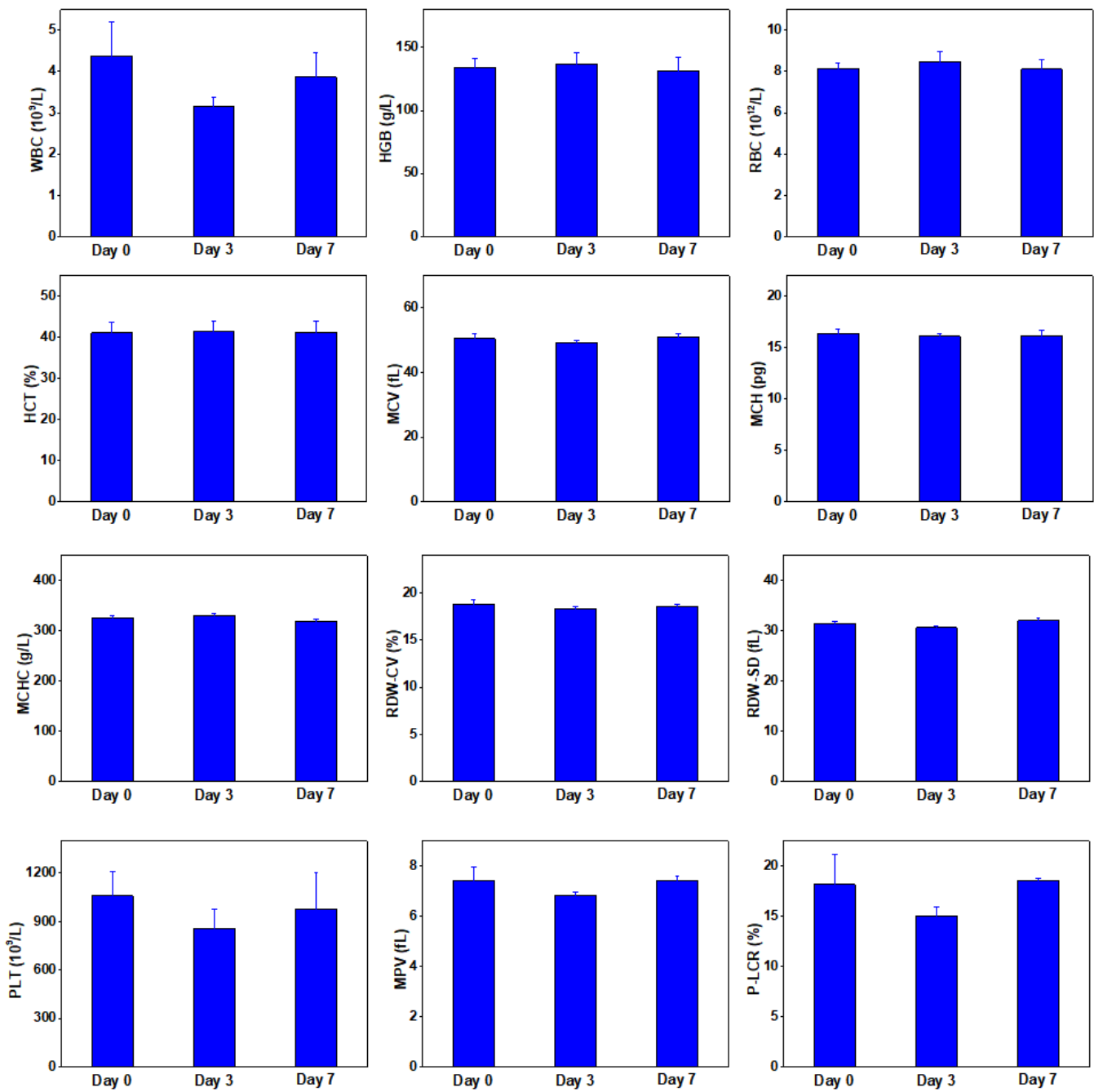

Figure S8. Hematological analysis of mice treated with GSE-HP. Data are mean \pm s.d. WBC, white blood cell; RBC, red blood cell; HGB, hemoglobin; MCHC, mean corpuscular hemoglobin concentration; RDW-SD, standard deviation of RBC distribution width; $\mathrm{MCH}$, mean corpuscular hemoglobin; $\mathrm{MCV}$, mean corpuscular volume; HCT, hematocrit; PLT, platelets; MPV, mean platelet volume. Mice were intravenously treated with GSE-HP $\left(8 \mathrm{mg} \cdot \mathrm{kg}^{-1}\right)$. Blood samples were collected for hematological analysis on day 0,3 and 7 after treatment. 


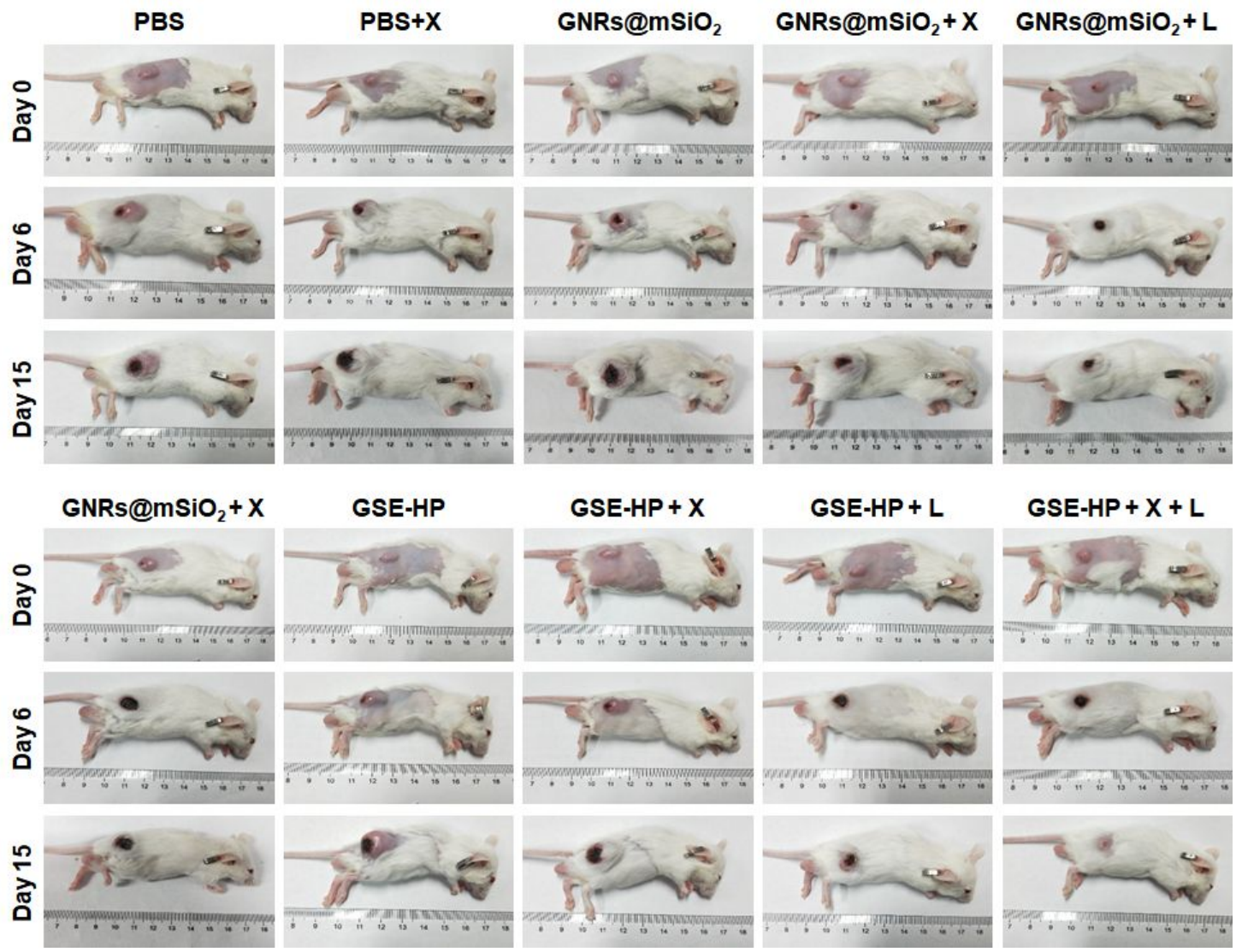

Figure S9. Representative photos of different groups of tumor-bearing mice after various treatments on day 0,6 , and 15 . 


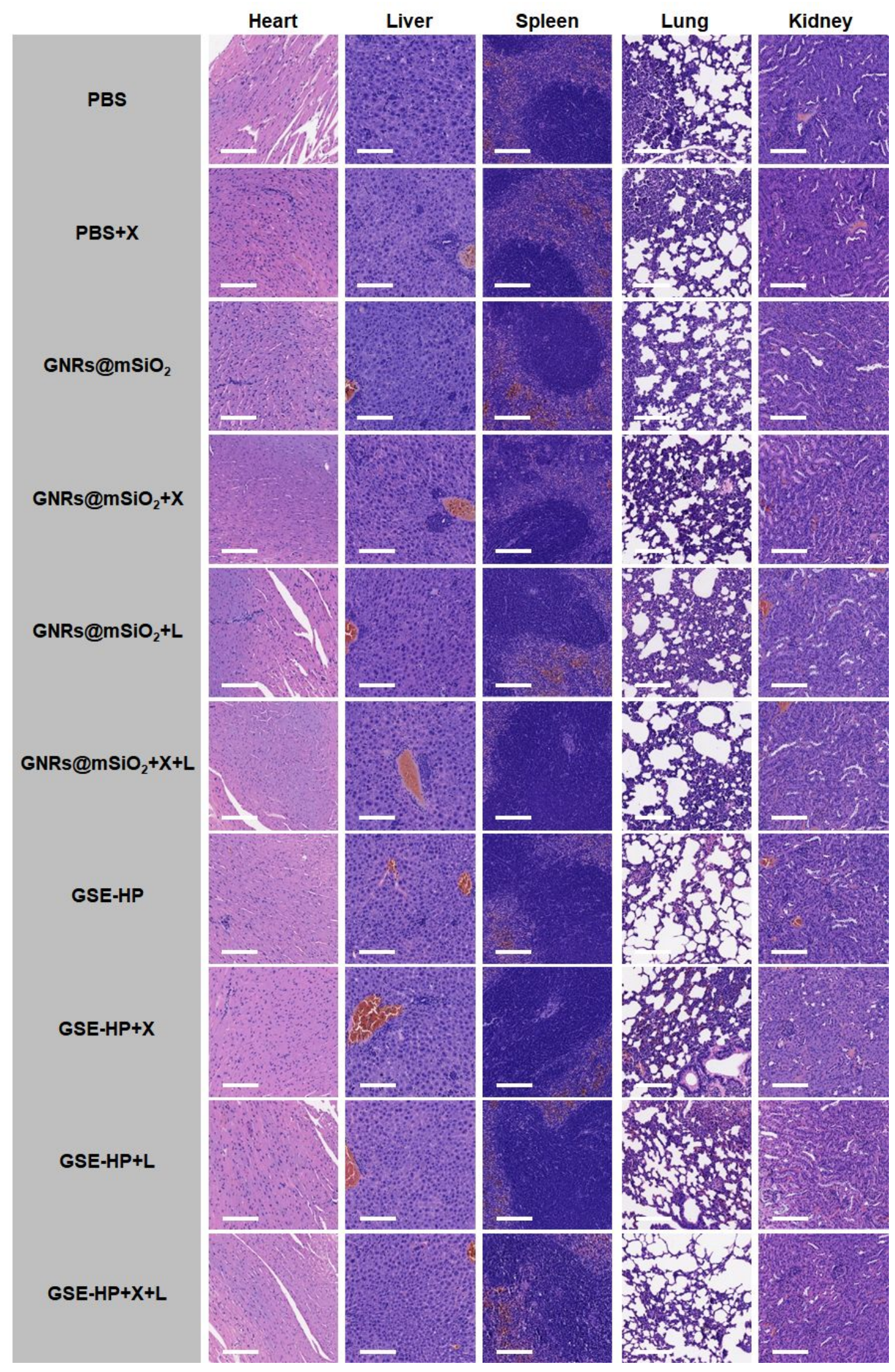

Figure S10. H\&E-staining of normal tissue slices after different treatments. 


\section{Reference}

1. Roper, D. K.; Ahn, W.; Hoepfner, M., Microscale Heat Transfer Transduced by Surface Plasmon Resonant Gold Nanoparticles. J. Phys. Chem. C 2007, 111 (9), 36363641 . 